\title{
Combined effects of local habitat, anthropogenic stress, and dispersal on stream ecosystems: a mesocosm experiment
}

\author{
Jarno Turunen (iD) $, 1,2,6$ Paulina Louhi, ${ }^{2,3}$ Heikki Mykrä, ${ }^{1}$ Jukka Arovitta, ${ }^{1}$ \\ Emmi Putkonen, ${ }^{2}$ Ari Huusko, ${ }^{4}$ And Timo Muotka ${ }^{2,5}$ \\ ${ }^{1}$ Freshwater Centre, Finnish Environment Institute, PO Box 413, 90014 Oulu, Finland \\ ${ }^{2}$ Department of Ecology and Genetics, University of Oulu, PO Box 8000, 90014 Oulu, Finland \\ ${ }^{3}$ Natural Resources Institute Finland (Luke), Paavo Havaksen tie 3, 90014 Oulu, Finland \\ ${ }^{4}$ Natural Resources Institute Finland (Luke), Manamansalontie 90, 88300 Paltamo, Finland \\ ${ }^{5}$ Natural Environment Centre, Finnish Environment Institute, PO Box 413, 90014 Oulu, Finland
}

\begin{abstract}
The effects of anthropogenic stressors on community structure and ecosystem functioning can be strongly influenced by local habitat structure and dispersal from source communities. Catchment land uses increase the input of fine sediments into stream channels, clogging the interstitial spaces of benthic habitats. Aquatic macrophytes enhance habitat heterogeneity and mediate important ecosystem functions, being thus a key component of habitat structure in many streams. Therefore, the recovery of macrophytes following in-stream habitat modification may be prerequisite for successful stream restoration. Restoration success is also affected by dispersal of organisms from the source community, with potentially the strongest responses in relatively isolated headwater sites that receive a limited amount of dispersing individuals. We used a factorial design in a set of stream mesocosms to study the independent and combined effects of an anthropogenic stressor (sand sedimentation), local habitat (macrophytes, i.e., moss transplants), and enhanced dispersal (two levels: high vs. low) on organic matter retention, algal accrual rate, leaf decomposition, and macroinvertebrate community structure. Overall, all responses were simple additive effects with no interactions between treatments. Sand reduced algal accumulation, total invertebrate density, and density of a few individual taxa. Mosses reduced algal accrual rate and algae-grazing invertebrates, but enhanced organic matter retention and the number of detritus and filter feeders. Mosses also reduced macroinvertebrate diversity by increasing the dominance by a few taxa. Mosses reduced leaf mass loss, possibly because the organic matter retained by mosses provided an additional food source for leaf-shredding invertebrates and thus reduced shredder aggregation into leaf packs. The effect of mosses on macroinvertebrate communities and ecosystem functioning was distinct irrespective of the level of dispersal, suggesting strong environmental control of community structure. The strong environmental control of macroinvertebrate community composition even under enhanced dispersal suggests that re-establishing key habitat features, such as natural stream vegetation, could aid ecosystem recovery in boreal streams.
\end{abstract}

Key words: benthic macroinvertebrates; community structure; connectivity; ecosystem function; fine sediments; leaf decomposition; macrophytes; mosses; restoration.

\section{INTRODUCTION}

Anthropogenic influences, such as land use and climate change, induce multiple stressors on ecosystems and result in changes in biodiversity and ecosystem functioning (Dirzo et al. 2014). However, the prediction of stressor effects is often difficult because stressor interactions have not been studied as thoroughly as individual stressors in isolation (Darling and Côté 2008, Jackson et al. 2016). Recently, many experimental studies have explored multiple-stressor effects of fine sediments, nutrients, pesticides, water temperature, and flow variability on stream biodiversity and ecosystem functioning (e.g., Matthaei et al. 2010, Magbanua et al. 2013, Mustonen et al. 2016). Such studies mostly focus on local, reach-scale factors, largely neglecting the regional control of diversity and community composition (Ricklefs 1987, Harrison and Cornell 2008). However, local habitat structure and connectivity within and among river networks may interact to modify ecological responses

Manuscript received 23 October 2017; revised 2 May 2018; accepted 23 May 2018. Corresponding Editor: Ryan S. King.

${ }^{6}$ E-mail: jarno.turunen@environment.fi to anthropogenic stressors, making prediction of stressor effects even more challenging (Hawkins et al. 1983, Sarremejane et al. 2017).

Land use for agriculture, forestry, and urbanization has vastly increased the erosion of sediments into stream channels (Waters 1995, Syvitski et al. 2005), with wide-ranging impacts on the ecological condition of streams (Matthaei et al. 2010, Piggot et al. 2015). Fine sediments fill the interstitial spaces of benthic habitats, thus reducing habitat availability for invertebrates and impairing the spawning success of gravel-spawning fishes (Kemp et al. 2011, Jones et al. 2012). Instable substrate also hinders the establishment of aquatic plants and sedentary invertebrates and scours periphytic algae (Wood and Armitage 1997, Jones et al. 2014, Turunen et al. 2017). Sedimentation may also alter ecosystem processes such as primary production (Louhi et al. 2017) and organic matter decomposition (Lecerf and Richardson 2010, Mustonen et al. 2016).

The positive effect of habitat heterogeneity on species diversity is one of the fundamental predictions of ecology (MacArthur 1965, Tews et al. 2004, Stein et al. 2014), although several recent studies have challenged the 
generality of this pattern (e.g., Bar-Massada and Wood 2014, Yang et al. 2015). Aquatic macrophytes are a key component of habitat structure and heterogeneity in many streams, as they increase diversity (Taniguchi et al. 2003, Suurkuukka et al. 2014) and temporal stability (Huttunen et al. 2017) of benthic communities, and modify ecosystem functioning by retaining both coarse and fine organic matter (Muotka and Laasonen 2002). Few invertebrates feed directly on macrophytes but use instead the fine organic matter retained by them, graze on epiphytic algae, or use macrophytes as refugia from high-flow events or predation (Suren and Winterbourn 1991, Rantala et al. 2004, Muotka and Syrjänen 2007). Excessive sedimentation can smother and eradicate stream macrophytes (Brookes 1986), especially mosses (Matthaei et al. 2006, Turunen et al. 2017). It is unclear, however, how macrophytes and fine sediments interact on community composition and ecosystem functioning and whether the detrimental effect of fine sediments is caused by sediments per se or as an indirect effect of macrophyte eradication (Turunen et al. 2017).

Dispersal can modify the responses of communities and ecosystem functions to local environmental conditions by increasing species diversity, stabilizing ecosystem functioning (Loreau et al. 2003, Cottenie and De Meester 2004, Venail et al. 2008), and facilitating the recovery of communities from disturbance (Reed et al. 2000). Highly heterogeneous habitats provide more niches for dispersing organism and may thus retain more species from source communities (Questad and Foster 2008, Matthiessen et al. 2010). Metacommunity models assume that if dispersal from the regional species pool is sufficient, species will track environmental conditions and become selected to localities based on interspecific fitness differences ("species sorting") (Leibold et al. 2004). In highly connected systems, dispersal from source communities provides a continuous supply of immigrants, potentially overwhelming the effects of local factors on community structure (source-sink dynamics). As a result, species may occur at environmentally non-optimal sites. Thus, high connectivity and extensive dispersal can homogenize local assemblages (Chase and Ryberg 2004, Lancaster and Downes 2017) and reduce the environmental control of community structure ("mass effects"; Mouquet and Loreau 2003, Cadotte and Fukami 2005). There is, however, also contrasting evidence showing that dispersal can promote the divergence of local assemblages by means of priority effects, thereby increasing $\beta$-diversity rather than decreasing it (Vannette and Fukami 2017).

The majority of stream restoration projects focus on reach-scale enhancement of habitat heterogeneity (Palmer et al. 2014). Enhanced heterogeneity is, however, likely to produce biodiversity benefits only if catchment scale stressors are alleviated (Sundermann et al. 2013, Turunen et al. 2016). Even then, at least two other factors control restoration success. First, full recovery of macrophyte beds may be a prerequisite for the recovery of benthic biodiversity and ecosystem functioning, particularly in regions where streams support naturally abundant in-stream vegetation (Muotka and Syrjänen 2007, Louhi et al. 2011). Second, increased habitat heterogeneity might not produce the desired outcome if organisms are unable to reach the restored sites because of dispersal constraints (Tonkin et al. 2014,
Winking et al. 2014). Conversely, very intensive dispersal may obscure any positive effects of restoration (Brown and Swan 2017). In this case, local communities are only weakly structured by environmental conditions and restoration that enhances habitat diversity may cause little observable effects on community structure. This result suggests that siting restoration measures appropriately is extremely relevant: a similar investment might yield a better outcome in more isolated headwater sites than in mainstem reaches (Brown and Swan 2017, Tornwall et al. 2017).

We used stream mesocosms to study the effects of an anthropogenic stressor (sand sedimentation), local habitat structure (aquatic mosses), and enhanced dispersal on organic matter retention, algal accrual rate, leaf decomposition, and macroinvertebrate communities. We asked (1) if disturbance by fine sand reduces ecosystem process rates and invertebrate diversity and abundance. Second, we asked (2) if invertebrate communities and ecosystem functions in moss-covered substrates differ from those in other substrate types and, more specifically, if mosses ameliorate the negative effects of fine sediments on invertebrate communities and ecosystem processes (antagonistic effect). Third, we asked (3) if mosses and enhanced dispersal interact synergistically to increase macroinvertebrate density or diversity more than expected based on mere additivity. In addition, we asked (4) if enhanced dispersal homogenizes communities and thereby masks the effects of local habitat factors (mosses; sand) on community structure (mass effects) or (5) whether macroinvertebrate community composition reflects mainly local habitat filters even at relatively high dispersal rates (species sorting).

\section{Materials And Methods}

We conducted the experiment in autumn 2014 in the Kainuu Fisheries Research Station of the Natural Resources Institute Finland (Luke; 64.24 $\mathrm{N} ; 27.31^{\circ} \mathrm{E}$ ). The station houses six $25 \times 1.5 \mathrm{~m}$ parallel outdoor channels with concrete walls and bottom covered by a $15-\mathrm{cm}$ layer of gravel-to-pebble-sized particles $(8-50 \mathrm{~mm}$ in diameter). The channels are $1.5 \mathrm{~m}$ away from each other. Water drains into the channels from a nearby lake; it then enters a $30 \mathrm{~m}$ long stream section before draining into the experimental arena. Thus, the channels receive a natural input of immigrating invertebrates and the benthic fauna within the channels resembles, with a few exceptions, that of nearby streams (Mustonen et al. 2016).

The experiment ran for $48 \mathrm{~d}$, from 14 August until 30 September 2014. Four $6 \mathrm{~m}$ long and $20 \mathrm{~cm}$ wide subflumes with walls made of rustproof metal sheets were placed parallel to each other within each of the six main channels (Figs. 1 and 2). Thus, the total number of subflumes was 24. Before the start of the experiment, the bottom of each subflume was covered by a uniform 10-cm layer of gravel, which was washed carefully to make sure that the experimental arena did not harbor any macroinvertebrates before the treatments were established. Water flow into the channels was adjusted such that every channel had similar flow velocity $(0.25-0.30 \mathrm{~m} / \mathrm{s})$ and water depth $(10-15 \mathrm{~cm})$. We manipulated three factors, with two levels each, in a split-plot factorial design (see Fig. 1). Habitat structure was simulated 

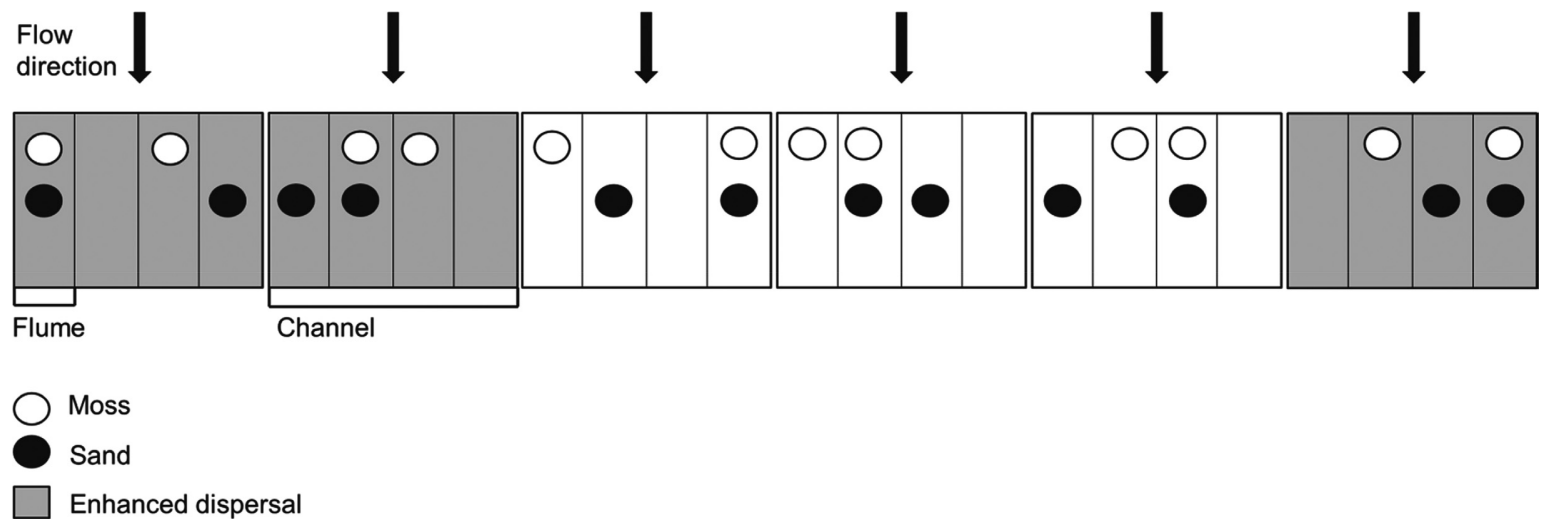

FIG. 1. Schematic presentation of the experimental design.

as the presence/absence of Fontinalis mosses, which are the major (often only) macrophytes in streams of the region. Most streams in our study area support dense moss growths (Turunen et al. 2017) and streams that have lost mosses as a result of human activities (channelization, sedimentation, installation of in-stream restoration structures) have also lost much of their organic matter retention capacity (Muotka and Syrjänen 2007). Therefore, the recovery of mosses can be considered as a key indicator of in-stream restoration success in boreal streams (Louhi et al. 2011). Land-use induced sedimentation was mimicked by addition of fine sand to predefined subflumes. Moss and sand treatments were allocated randomly across the four subflumes within each channel (Figs. 1 and 2). Connectivity to regional species pool was mimicked by addition of benthic invertebrates (hereafter, "enhanced dispersal"); this experimental factor was thus implemented at the whole-channel scale, with all subflumes in three randomly selected channels receiving extra loads of invertebrates, while the other set of $12(3 \times 4)$ subflumes only received invertebrates from the upstream section of the experimental arena (Figs. 1 and 2). The intention of our dispersal treatment was to remove dispersal limitation and thus mimic a mass-effects situation.

Mosses (Fontinalis antipyretica Hedw.) for the experiment were collected from the stream reach upstream of the channels. Mosses were washed vigorously in the stream water and then dried in open sunlight for a few hours to remove most macroinvertebrates. Close examination of several moss tufts showed that, following this treatment, very few invertebrates were introduced into the experimental arena with the moss transplants. Moss tufts were attached to cobble-sized stones (80-120 mm diameter) with a cable tie. Four moss-covered stones were added to predefined subflumes, resulting in $\sim 40 \%$ coverage. This level of moss cover corresponds well with that observed in natural streams in northern Finland (Turunen et al. 2017). The same number of cobble-sized stones without mosses was added to all other subflumes.

Sand of two different size classes, fine $(<2 \mathrm{~mm}$ diameter $)$ and coarse (2-3 $\mathrm{mm}$ diameter), was transferred from a local gravel mining pit. Ten liters of fine sand and $10 \mathrm{~L}$ of coarse sand were introduced to each subflume designated to receive the sedimentation treatment, resulting in $\sim 60 \%$ cover of sand, which corresponds well to the level observed in sedimentimpacted streams in our study region (Turunen et al. 2017).
After the moss and sand treatments were established, an extra load of invertebrates was added to each subflume of the three predefined (randomly selected) channels, indicating the start (day 1) of the experiment (Fig. 1). Each subflume received a 1-min kick net sample of invertebrates from a nearby stream. A 3-min kick net sample was added to the same subflumes three weeks after the onset of the experiment (day 22) and another 1-min sample again on day 41 . To estimate the assemblage composition of the added samples, we also collected three 1-min kick net samples (day 22) from the same stream and identified invertebrates in the laboratory (Appendix S1).

Algal accrual rate was measured by incubating four 25$\mathrm{cm}^{2}$ ceramic tiles in each subflume for the duration of the

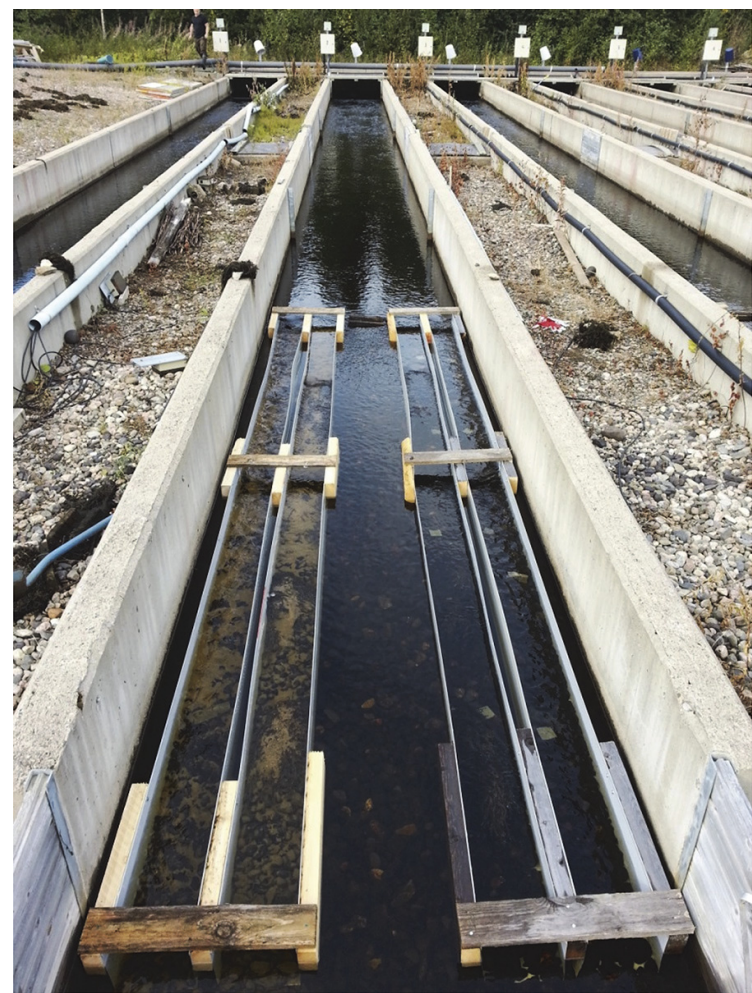

FIG. 2. A picture showing one of the six main channels and the four subflumes to which the treatments were allocated. Treatments, from left to right, are sand, moss $\times$ sand, moss, control. 
experiment. At the end of the experiment, the tiles were collected, sealed with aluminum foil, and frozen. In the laboratory, periphyton was brushed off the tiles and its biomass (chlorophyll a) was measured spectrophotometrically by using national standards (National Board of Waters 1981).

To measure leaf breakdown, we collected alder (Alnus incana L.) leaves prior to abscission and dried them in room temperature $\left(22^{\circ} \mathrm{C}\right)$ for three weeks. We then fastened $2 \mathrm{~g}$ of leaf material with paper clips to create leaf packs. Four leaf packs were placed in each subflume on the third week of the experiment (day 22) so that total incubation period was $27 \mathrm{~d}$. By the end of the incubation period, leaf packs were collected and immediately frozen. In the laboratory, invertebrates were collected and identified and other material was removed from the samples. The remaining leaf material was dried for $24 \mathrm{~h}$ at $60^{\circ} \mathrm{C}$ and weighed. The samples were then ashed for $4 \mathrm{~h}$ at $550^{\circ} \mathrm{C}$ to convert dry mass to ash-free dry mass and the percentage of leaf mass loss was then calculated.

Macroinvertebrates were sampled in each subflume by taking four Surber samples (mesh size $0.5 \mathrm{~mm}$, sampling area $290 \mathrm{~cm}^{2}$ ) by disturbing the bottom sediment with hand for $30 \mathrm{~s}$. Samples were positioned at regular intervals in each subflume $(0.5,2.0,3.5$, and $5.0 \mathrm{~m}$ from the downstream end of a subflume). Samples were preserved in $70 \%$ ethanol and all specimens were identified in the laboratory to species or genus level, except Chironomidae, which were identified to subfamily. Simuliidae and Oligochaeta were not identified further.

After invertebrates were collected, the remaining material was filtered through two filters with mesh sizes of 1.0 and $0.2 \mathrm{~mm}$. Thus, organic matter was sorted in two size classes, coarse $(\mathrm{CPOM} ;>1.0 \mathrm{~mm})$ and fine particulate organic matter (FPOM; 0.2-1.0 mm). Samples were then dried, ashed and weighed following the same protocol as for the leaf material. All response variables were sampled only once on the last day of the experiment.

\section{Statistical analyses}

We analyzed differences among treatments in algal accrual rate $\left(\mu \mathrm{g} \cdot \mathrm{cm}^{-2} \cdot \mathrm{d}^{-1}\right)$, leaf mass loss $(\%$; logit-transformed), organic matter standing stock $\left(\mathrm{g} / \mathrm{m}^{2}\right)$, and macroinvertebrate responses (total density, species richness, and diversity) using linear mixed effects models (LMM; function lme in R package nlme; Pinheiro et al. 2017), following topdown strategy (Zuur et al. 2009). Thus, our initial "full model" included the main effects of moss, sand, and enhanced dispersal as fixed factors and channels and subflumes nested within channels as random variables. For model selection, we used compared $\mathrm{AIC}_{\mathrm{c}}$ (Akaike's information criterion, corrected for small sample sizes) values between proceeding models and selected the model with the lowest AIC value. As our initial random effects (channels, subflumes nested within channels, and samples nested within effects) were all non-significant (i.e., did not improve model fit significantly), they were removed from the models (Zuur et al. 2009). Following the same logic, all non-significant three- and two-way interactions were excluded. Thus, our final analysis consisted of generalized least square models (GLS in R package nlme; Pinheiro et al. 2017) with only main effects and significant interactions included. Variance structure (VarIdent) was included to allow for heterogeneity in variance among moss treatments. Total species richness was analysed using the same procedure, but with the glm function and Poisson error distribution.

We explored the effect of each main treatment on macroinvertebrate community composition by using nonmetric multidimensional scaling (NMS) ordination based on BrayCurtis distances. Densities were $\ln (x+1)$-transformed prior to the analysis. A three-dimensional solution for NMS was used as subsequent dimensions did not decrease stress appreciably. The effects of treatments on assemblage composition were tested with Permutational Multivariate Analysis of Variance (PERMANOVA; Anderson 2001) using the function adonis in vegan (Oksanen et al. 2015). Prior to PERMANOVA, we tested for homogeneity of multivariate dispersion within treatments with Permutational Analysis of Multivariate Dispersions (PERMDISP; Anderson 2006) using the function betadisper in vegan (Oksanen et al. 2015).

In case of significant main effects in PERMANOVA, we used indicator species analysis (IndVal; Dufrêne and Legendre1997) in the R package labdsv (Roberts 2012) to identify potential indicator taxa for each main effect. IndVal analysis yields an indicator value (IV) for a species in each a priori defined site group. IV for a taxon varies from 0 to 100 , and it attains its maximum value when all individuals of a taxon occur at all sites of a single group. Significance of the indicator value for each taxon was tested by a Monte Carlo randomization test with 1,000 permutations. We considered species with IV $>60$ (and significant at $\alpha=0.05$ ) to be strong indicators.

\section{RESUlts}

\section{Organic matter standing stock, algal accrual rate, and leaf decomposition}

All ecosystem functions exhibited only simple additive effects with no interactions. Both mosses $(t=6.67$, $P<0.001)$ and sand $(t=3.18, P=0.002)$ increased FPOM retention (Fig. 3a) but only mosses increased retention of CPOM ( $t=2.88, P=0.005$; Fig. $3 b)$.

Algal accrual was negatively affected by both mosses $(t=-4.09, P<0.001)$, sand $(t=-2.40, P=0.018)$ and dispersal $(t=-4.87, P<0.001$; Fig $3 \mathrm{c})$. Mosses also reduced leaf mass loss $(t=-3.55, P<0.001)$ while enhanced dispersal increased decomposition rate $(t=2.73, P=0.008$; Fig. $3 \mathrm{~d})$.

\section{Macroinvertebrate responses: density and diversity}

Mosses $(t=3.56, P<0.001)$ and dispersal $(t=3.66$, $P<0.001)$ increased invertebrate density, while sand reduced it $(t=-2.12, P=0.037$; Fig. $4 \mathrm{a})$. Mosses had a negative $(t=-2.14, P=0.032)$ and enhanced dispersal positive ( $t=2.00, P=0.0045)$ effect on invertebrate taxon richness. Simpson diversity was reduced by mosses $(t=-7.98$, $P<0.001$; Fig. 4c).

Shredder abundance in leaf packs was positively related to leaf mass loss (linear regression, $F_{1,22}=22.51, R^{2}=0.48$, $P<0.001)$. Mosses reduced abundance of shredders in leaf packs $(t=-3.86, P<0.001)$ but not in benthic samples $(t=-1.22, P=0.226)$. 

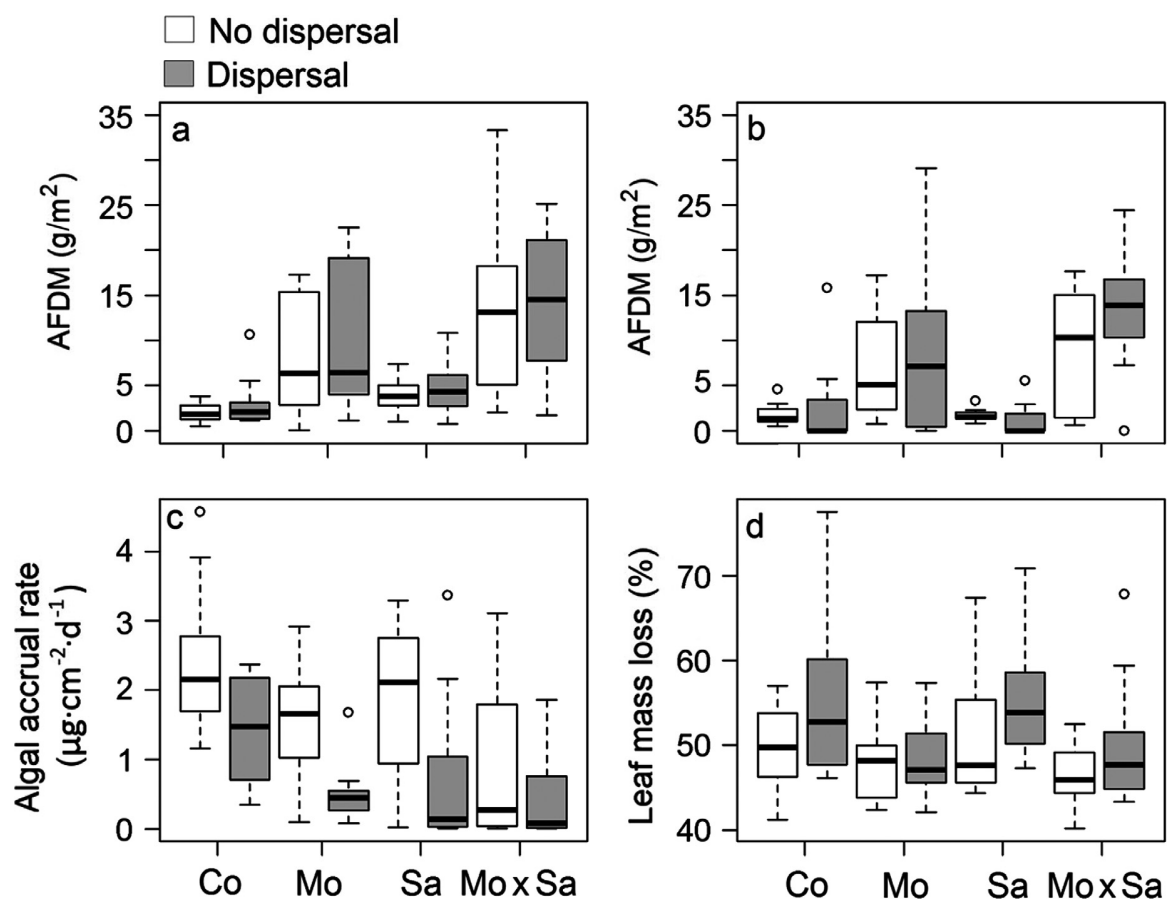

FIG. 3. Variation of ash-free dry mass (AFDM) of (a) fine and (b) coarse particulate organic matter, (c) algal accrual rate, and (d) leaf mass loss in each treatment. The boxes display first and third quartiles, thick lines are medians, whiskers are range, and open circles are outliers. Co, control (gravel/pebble); Mo, moss; and Sa, sand.
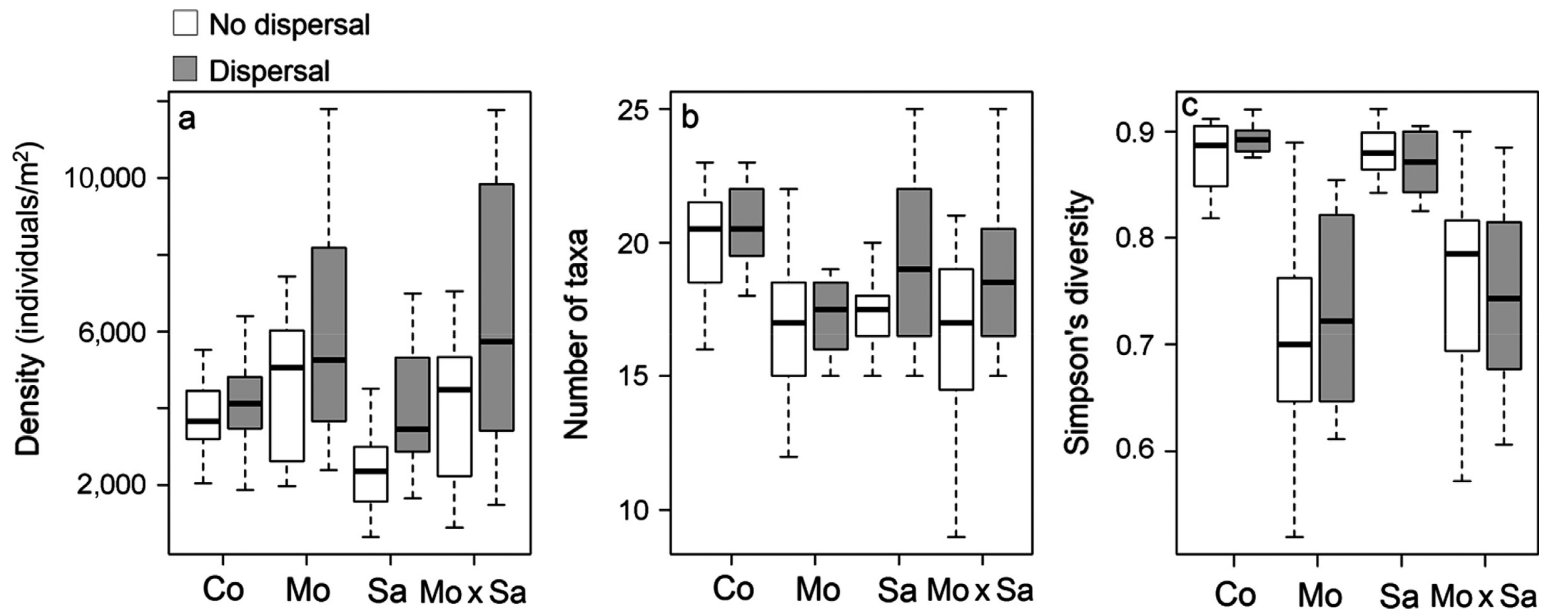

FIG. 4. Variation of (a) total invertebrate density, (b) richness, and (c) Simpson diversity in each treatment. The boxes display first and third quartiles, thick lines are medians, whiskers are range, and open circles are outliers. Co, control (gravel/pebble); Mo, moss; and Sa, sand.

\section{Macroinvertebrate responses: community composition}

Mosses (PERMANOVA, $F_{1,23}=5.74, \quad R^{2}=0.16$, $P<0.001$; Fig. 5a) and dispersal $\left(F_{1,23}=7.47, R^{2}=0.20\right.$, $P<0.001$; Fig. 5c) had a significant main effect on invertebrate community composition, as did sand, albeit less so $\left(F_{1,23}=2.93, R^{2}=0.08, P=0.004\right.$; Fig. $\left.5 b\right)$. No significant interactions were detected. Within-treatment community variability was negligible for all main effects (PERMDISP, all $P>0.50)$.

Indicator value analysis identified several taxa associated with each main effect (Table 1). Heptagenidae and Baetidae mayflies indicated the absence of mosses, suggesting that the grazing feeding mode and preference for high water velocity were favored in subflumes lacking mosses (Table 1). Leptophlebia sp. mayflies, chironomid dipterans, Nemoura sp. stoneflies, and the caddis larva Hydropsyche siltalai were indicators for the presence of mosses, suggesting that detritivory was a favored feeding trait in moss treatments (Table 1). Chironominae, Heptagenia sulphurea, Leptophlebia sp., and Polycentropus flavomaculatus, a net-spinning caddisfly, were sensitive to sand sedimentation, whereas the mayfly Caenis rivulorum was the only species that seemed to benefit from sand (Table 1). Treatments 

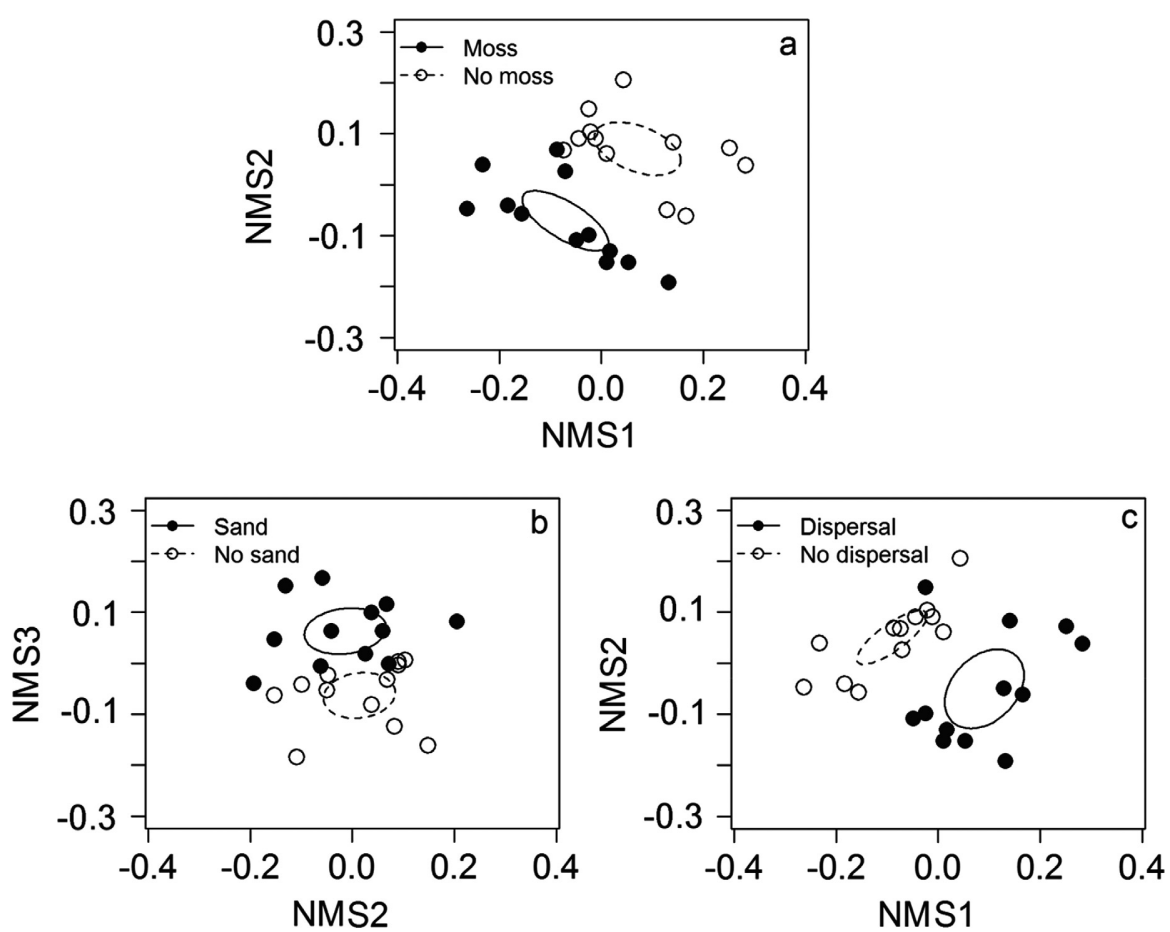

FIG. 5. Nonmetric multidimensional scaling (NMS) ordinations for the main effects of mosses (a), sand (b), dispersal (c), with 95\% confidence ellipses around centroids.

receiving enhanced dispersal were indicated by hydropsychid caddis larvae (Cheumatopsyche lepida, Hydropsyche ssp.), shredding invertebrates (Lepidostoma hirtum, Asellus aquaticus), and sphearid mussels, whereas P. flavomacualtus and the snail Radix peregra occurred mainly in flumes with no added dispersal.

\section{Discussion}

Variation in local habitat structure and dispersal intensity can be expected to interact in how they influence the responses of communities and ecosystem functions to anthropogenic stressors (Venail et al. 2008, Sarremejane et al. 2017). We manipulated the level of sedimentation (stressor), presence of mosses (habitat structure), and dispersal to explore the relative importance of, and interactions between, these local- vs. regional-scale determinants of lotic communities. Multiple, simultaneously operating factors often yield non-additive responses, and such antagonistic or synergistic responses may be more common in nature than simple additive effects of individual stressors (Darling and Côté 2008, Jackson et al. 2016). In our experiment, however, all effects of mosses, sand and enhanced dispersal were simple main effects, suggesting that each factor acted mainly independently. We expected sedimentation to have a negative effect on most response variables but this was only observed for algal accrual rate, total invertebrate density, and a few sensitive taxa. Our expectation that mosses would ameliorate the negative effects of sand was mainly not supported as these factors acted additively. Conversely, sand did not cancel the positive effects of mosses on invertebrate density.

\section{Ecosystem functions}

Aquatic macrophytes are often a key retentive structure in headwater streams and they also increase stream habitat heterogeneity (Muotka and Laasonen 2002, Taniguchi et al. 2003). Fontinalis mosses in particular have such a key role in boreal streams (Koljonen et al. 2012) and this was also observed in our experiment where mosses enhanced greatly the retention of both FPOM and CPOM. Thus, organic matter standing stock in moss-containing streams may be almost an order of magnitude higher than in streams lacking mosses, highlighting the indirect importance of mosses, or macrophytes in general, in fueling detritus-based stream food webs.

Algal accrual rate was negatively impacted by all experimental factors (mosses, sand, and dispersal). Negative effects of mosses on algal accumulation were likely related to shading, nutrient competition, and reduced current velocity (Horner and Welch 1981). Reduced algal production in treatments with sand reflects burial, scouring, and shading of algae by sand (Jones et al. 2014, Mustonen et al. 2016, Louhi et al. 2017). Enhanced dispersal also reduced algal accrual rate, although it did not seem to benefit grazing invertebrates. However, dispersal did increase relative abundance of shredders (e.g., Lepidostoma hirtum, Asellus aquaticus), which are known to consume periphyton, sometimes even preferring periphyton over detritus as their food source (Friberg and Jacobsen 1994, Ledger and Hildrew 2005). It is thus possible that the negative effect of dispersal on algal accrual was at least partly caused by increased consumption of periphyton by shredding invertebrates. 
TABLE 1. Macroinvertebrate indicator taxa for each main effect, together with their indicator values (IV) and associated $P$ values.

\begin{tabular}{|c|c|c|c|}
\hline Treatment and taxa & Order & IV & $P$ \\
\hline \multicolumn{4}{|l|}{ No moss } \\
\hline Heptagenia sulphurea Müller & Ephemeroptera & 0.81 & 0.002 \\
\hline Baetis rhodani Pictet & Ephemeroptera & 0.79 & 0.001 \\
\hline Baetis fuscatus Linnaeus & Ephemeroptera & 0.78 & 0.001 \\
\hline Baetis muticus Linnaeus & Ephemeroptera & 0.72 & 0.001 \\
\hline Rhyacophila nubila Zetterstedt & Trichoptera & 0.71 & 0.002 \\
\hline Kageronia fuscogrisea Retzius & Ephemeroptera & 0.70 & 0.030 \\
\hline Isoperla sp. & Plecoptera & 0.65 & 0.001 \\
\hline \multicolumn{4}{|l|}{ Moss } \\
\hline Tanypodinae (Chironomic & Diptera & 0.79 & 0.001 \\
\hline Leptophlebia sp. & Ephemeroptera & 0.78 & 0.001 \\
\hline Hydropsyche siltalai Doehler & Trichoptera & 0.69 & 0.025 \\
\hline Nemoura sp. & Plecoptera & 0.69 & 0.014 \\
\hline Ortho & Diptera & 0.67 & 0.040 \\
\hline Chirono & Diptera & 0.62 & 0.047 \\
\hline \multicolumn{4}{|l|}{ No sand } \\
\hline Chironom & Dipt & 0.76 & 0.005 \\
\hline $\begin{array}{l}\text { Polycentropus flavomaculatus } \\
\text { Pictet }\end{array}$ & Trichoptera & 0.76 & 0.001 \\
\hline Heptagenia sulphurea & Ephemeroptera & 0.73 & 0.021 \\
\hline Leptophlebia sp. & Ephemero & 0.73 & 0.001 \\
\hline \multicolumn{4}{|l|}{ Sand } \\
\hline Caenis rivulorum Eaton & Ephemeroptera & 0.63 & 0.037 \\
\hline \multicolumn{4}{|l|}{ No dispersal } \\
\hline Radix peres & $\mathrm{Ga}$ & 0.71 & 0.038 \\
\hline Polycentropus flavomaculatus & Trichoptera & 0.66 & 0.032 \\
\hline \multicolumn{4}{|l|}{ Dispersal } \\
\hline Cheumatopsyche lepida Pictet & Tricho & 0.83 & 0.001 \\
\hline Hydropsyche siltalai & Trichoptera & 0.78 & 0.001 \\
\hline Pisidium sp. & Bivalvia & 0.75 & 0.001 \\
\hline Sphaerium sp. & Bivalvia & 0.75 & 0.002 \\
\hline Hydropsyche pellucidula Curtis & Trichoptera & 0.75 & 0.001 \\
\hline Orthocladiinae & Diptera & 0.67 & 0.040 \\
\hline Lepidostoma hirtum Fabricius & Trichoptera & 0.67 & 0.040 \\
\hline Asellus aquaticus Linnaeus & Isopoda & 0.67 & 0.010 \\
\hline
\end{tabular}

Leaf decomposition was reduced in the presence of mosses and increased by enhanced dispersal but was not affected by sand. Lack of response to sand confirms the result of previous field (Turunen et al. 2017) and experimental (Mustonen et al. 2016) studies in the same region and experimental venue, respectively. Effects of sedimentation on leaf decomposition seem to be strongly context dependent, as some studies in North America have reported negative effects (Lecerf and Richardson 2010, Louhi et al. 2017), while those in New Zealand have commonly observed sedimentation to increase decomposition rate (Matthaei et al. 2010, Piggott et al. 2015). In our experiment, sand did not reduce abundances of shredding invertebrates, which was likely the reason for the low effect of sand on leaf decomposition, as the rather strong positive relationship between leaf mass loss and shredder abundance suggested that shredders were largely responsible for mediating this ecosystem process. The positive effect of enhanced dispersal on decomposition likely reflected the increased abundance of leaf-shredding invertebrates in dispersal treatments. Shredder abundance in leaf packs was lower when mosses were present, although mosses did not reduce shredder abundance at the whole-flume scale, suggesting shredder aggregation in leaf packs when no moss-retained organic matter was available. Thus, lower shredder aggregation was likely the mechanism causing the reduced decomposition in the moss treatment.

\section{Macroinvertebrate responses}

Total macroinvertebrate density increased, but richness and diversity decreased, in moss-containing flumes. This was because the dominance by certain taxa increased in moss treatments. The presence of mosses was a stronger habitat filter for macroinvertebrate communities than was the presence of sand. Detritus feeders (Leptophlebia sp., Orthocladiinae, Chironominae), filter feeders (Hydropsyche ssp.), and some predators (Tanypodinae) particularly benefited from mosses. Moss tufts harbor abundant communities of protozoans, microcrustaceans, and other microarthropods that are major prey for Tanypodinae (Suren 1993, Linhart et al. 2002), although they also frequently ingest detritus (Armitage et al. 1995). When both mosses and sand were present, communities were similar to treatments with only moss, suggesting that mosses buffered the detrimental effects of sand. For example, Chironominae and Leptophlebia sp. were reduced by sand, but sand did not cancel the positive effect of mosses. Mosses had a clearly negative effect on grazing mayflies (Baetidea, Heptageniidae), likely as a result of decreased algal biomass in moss-containing flumes.

The role of mosses in shaping community composition remained practically the same even under enhanced dispersal, again suggesting strong environmental control by mosses on invertebrate community assembly. At first glance, this result appears to be in conflict with the view that communities in highly connected reaches receiving abundant dispersers should be controlled by mass effects rather than by the local environment (Brown and Swan 2010). However, while the extra loads of invertebrates introduced into the experimental arena clearly removed dispersal limitation, with flumes that received added invertebrates containing several species that were completely absent or very rare in other flumes (but present in the nearby river), we cannot be sure if it was sufficient to produce mass effects in the recipient community. Indeed, as our current knowledge about dispersal rates and distances of aquatic invertebrates is highly rudimentary, manipulating dispersal at realistic scales presents a major challenge to experimental stream ecology (but see Lancaster and Downes 2017).

Sedimentation commonly reduces macroinvertebrate richness and diversity (Elbrecht et al. 2016, Louhi et al. 2017, Turunen et al. 2017), especially those of EPT (Ephemeroptera, Trichoptera, Plecoptera) taxa (Townsend et al. 2008, Larsen et al. 2011, Wagenhoff et al. 2012). In our experiment, sand reduced total invertebrate density and altered their community composition but had no effect on taxonomic richness, similar to an earlier study in the same experimental venue (Mustonen et al. 2016). Our experimental channels had a $10-\mathrm{cm}$ gravel layer that could have provided relatively stable substrate for invertebrates and thus partly explain the rather weak responses to sedimentation compared to many previous experiments (Shaw and Richardson 2001, Wagenhoff et al. 2012). The negative 
effects of sand were restricted to a few sensitive taxa (Chironominae, Leptophelebia sp., Heptagenia sulphurea, Polycentropus flavomaculatus). Reduction of chironomids due to sedimentation is contrary to the notion that Chironomidae are generally tolerant of anthropogenic stressors, including sedimentation (e.g., Zweig and Rabeni 2001, Kreutzweiser et al. 2005). It is likely, however, that species within this diverse family vary greatly in sensitivity to sedimentation (Elbrecht et al. 2016). In our experiment, indicator value analysis identified the subfamily Chironominae as highly sensitive to sedimentation. Algal grazers such as Heptagenia sulphurea were also reduced by sand, due likely to sedimentation-induced decrease of algal production and quality (Broekhuizen et al. 2001, Peeters et al. 2006). Polycentropus flavomaculatus, a net-spinning caddis larva, was also negatively affected by sand, likely because moving sand particles damaged their nets.

Enhanced dispersal increased total density and number of invertebrate taxa, and this increase was mostly attributable to hydropsychid caddis larvae, sphaeriids, and shredding invertebrates (especially Lepidostoma hirtum and Asellus aquaticus). The positive effect of dispersal on invertebrate density and richness was similar when sand and moss were present, as suggested by the lack of interactions. Enhanced dispersal also affected some species, probably by intensifying biological interactions. For example, the near lack of Polycentropus flavomaculatus from treatments with enhanced dispersal coincided with increased abundance of another filter-feeding caddis, Hydropsyche spp., suggesting intensified interspecific competition for net-building sites. While enhanced dispersal did have an effect on community structure, it did not blur the effects of mosses and sand, with no indication of enhanced dispersal homogenizing invertebrate community structure across treatments.

Overall, our results highlight that local habitat structure, anthropogenic stress, and enhanced dispersal acted mostly independently and the responses to any combination of these factors were mainly predictable based on their singlefactor effects. Local habitat factors had a distinct effect on community composition and ecosystem functions even under anthropogenic stress. Similarly, dispersal had a distinct imprint on community composition but the effects of habitat structure remained the same even under enhanced dispersal, suggesting strong environmental control of stream benthic communities.

\section{Implications for stream restoration}

In-stream restoration typically uses heavy machinery to conduct the restoration work, usually with the desired outcome of increasing streambed heterogeneity (Marttila et al. 2016). On a negative side, restoration operations may eradicate macrophytes, causing a massive reduction of macrophyte biomass across large spatial scales (Muotka and Laasonen 2002, Louhi et al. 2011). Our results suggest that the recovery of aquatic macrophytes is pivotal for the full ecological recovery of streams that naturally support extensive macrophyte growth. The strong effect of macrophytes on community composition even under intensive dispersal suggests that local habitat heterogeneity may alter stream macroinvertebrate communities even in highly connected sites that experience substantial immigration. This partly contrasts with the contention that isolated headwater sites are more environmentally controlled (Brown and Swan 2010) and should therefore be more responsive to habitat manipulation than are midstream reaches (Brown and Swan 2017, Tornwall et al. 2017). Our results suggest that key habitat features, such as mosses in boreal streams, may have an overriding imprint on local community structure and ecosystem functions and should therefore be the main target of restoration efforts in boreal streams.

\section{ACKNOWLEDGMENTS}

We thank the personnel of the Kainuu Fisheries Research Station for helping with the maintenance of the experimental system. This work was funded by the Academy of Finland (grant no 263597) and Maa-ja vesitekniikan tuki ry foundation. This paper is also part of the MARS project (Managing Aquatic ecosystems and water Resources under multiple Stress) funded under the 7th EU Framework Programme, Theme 6 (Environment including Climate Change), contract no. 603378. We acknowledge comments by Cayetano Gutiérrez-Cánovas and an anonymous referee on a previous draft of our manuscript.

\section{Literature Cited}

Anderson, M. J. 2001. A new method for non-parametric multivariate analysis of variance. Austral Ecology 26:32-46.

Anderson, M. J. 2006. Distance-based tests for homogeneity of multivariate dispersions. Biometrics 62:245-253.

Armitage, P., P. S. Cranston, and L. C. V. Pinder. 1995. The Chironomidae: biology and ecology of non-biting midges. Chapman and Hall, London, UK.

Bar-Massada, A., and E. M. Wood. 2014. The richness-heterogeneity relationship differs between heterogeneity measures within and among habitats. Ecography 37:528-535.

Broekhuizen, N., S. Parkyn, and D. Miller. 2001. Fine sediment effects on feeding and growth in the invertebrate grazers Potamopyrgus antipodarum (Gastropoda, Hydrobiidae) and Deleatidium sp. (Ephemeroptera, Leptophlebiidae). Hydrobiologia 457:125-132.

Brookes, A. 1986. Responses of aquatic vegetation to sedimentation downstream from river channelization works in England and Wales. Biological Conservation 38:351-367.

Brown, B. L., and C. M. Swan. 2010. Dendritic network structure constrains metacommunity properties in riverine ecosystems. Journal of Animal Ecology 79:571-580.

Brown, B. L., and C. M. Swan. 2017. Metacommunity theory meets restoration: isolation may mediate how ecological communities respond to stream restoration. Ecological Applications 27:22092219.

Cadotte, M. W., and T. Fukami. 2005. Dispersal, spatial scale, and species diversity in a hierarchically structured experimental landscape. Ecology Letters 8:548-557.

Chase, J. M., and W. A. Ryberg. 2004. Connectivity, scale-dependence, and the productivity-diversity relationship. Ecology Letters 7:676-683.

Cottenie, K., and L. De Meester. 2004. Metacommunity structure: synergy of biotic interactions as selective agents and dispersal as fuel. Ecology 85:114-119.

Darling, E. S., and I. M. Côté. 2008. Quantifying the evidence for ecological synergies. Ecology Letters 11:1278-1286.

Dirzo, R., H. S. Young, M. Galetti, G. Ceballos, N. J. B. Isaac, and B. Collen. 2014. Defaunation in the Anthropocene. Science 345:401-406.

Dufrêne, M., and P. Legendre. 1997. Species assemblages and indicator species: the need for a flexible asymmetrical approach. Ecological Monographs 67:345-366.

Elbrecht, V., A. J. Beermann, G. Goessler, J. Neumann, R. Tollrian, R. Wagner, A. Wlecklik, J. J. Piggot, C. D. Matthaei, and F. Leese. 
2016. Multiple-stressor effects on stream invertebrates: a mesocosm experiment manipulating nutrients, fine sediment and flow velocity. Freshwater Biology 61:362-375.

Friberg, N., and D. Jacobsen. 1994. Feeding plasticity of two detrivore-shredders. Freshwater Biology 32:133-142.

Harrison, S., and H. Cornell. 2008. Toward a better understanding of the regional causes of local community richness. Ecology Letters 11:969-979.

Hawkins, C. P., M. L. Murphy, N. H. Anderson, and M. A. Wilzbach. 1983. Density of fish and salamanders in relation to riparian canopy and physical habitat in streams of the northwestern United States. Canadian Journal of Fisheries and Aquatic Sciences 40:1173-1185.

Horner, R. R., and E. B. Welch. 1981. Stream periphyton development in relation to current velocity and nutrients. Canadian Journal of Fisheries and Aquatic Sciences 38:449-457.

Huttunen, K.-L., H. Mykrä, J. Oksanen, A. Astorga, R. Paavola, and T. Muotka. 2017. Habitat connectivity and in-stream vegetation control temporal variability of benthic invertebrate communities. Scientific Reports 7:1448.

Jackson, M. J., C. J. G. Loewen, R. D. Vinebrooke, and C. T. Chimimba. 2016. Net effects of multiple stressors in freshwater ecosystems: a meta-analysis. Global Change Biology 22:180-189.

Jones, J. I., J. F. Murphy, A. L. Collins, D. A. Sear, P. S. Naden, and P. D. Armitage. 2012. The impact of fine sediment on macroinvertebrates. River Research and Applications 28:1055-1071.

Jones, J. I., C. P. Duerdoth, A. L. Collins, P. S. Naden, and D. A. Sear. 2014. Interactions between diatoms and fine sediment. Hydrological Processes 28:1226-1237.

Kemp, P., D. Sear, A. Collins, P. Naden, and I. Jones. 2011. The impacts of fine sediment on riverine fish. Hydrological Processes 25:1800-1821.

Koljonen, S., P. Louhi, A. Mäki-Petäys, A. Huusko, and T. Muotka. 2012. Quantifying the effects of in-stream habitat structure and discharge on leaf retention: implications for stream restoration. Freshwater Science 31:1121-1130.

Kreutzweiser, D. P., S. S. Capell, and K. P. Good. 2005. Effects of fine sediment inputs from a logging road on stream insect communities: a large-scale experimental approach in a Canadian headwater stream. Aquatic Ecology 39:55-66.

Lancaster, J., and B. J. Downes. 2017. A landscape-scale field experiment reveals the importance of dispersal in a resource-limited metacommunity. Ecology 98:565-575.

Larsen, S., G. Pace, and S. J. Ormerod. 2011. Experimental effects of sediment deposition on the structure and function of macroinvertebrate assemblages in temperate streams. River Research and Applications 27:257-267.

Lecerf, A., and J. S. Richardson. 2010. Litter decomposition can detect effects of high and moderate levels of forest disturbance on stream condition. Forest Ecology and Management 259:2433-2443.

Ledger, M. E., and A. G. Hildrew. 2005. The ecology of acidification and recovery: changes in herbivore-algal food web linkages across a stream pH gradient. Environmental Pollution 137:103-118.

Leibold, M. A., et al. 2004. The metacommunity concept: a framework for multi-scale community ecology. Ecology Letters 7:601613.

Linhart, J., S. Vlčková, and V. Uvíra. 2002. Bryophytes as a special mesohabitat for meiofauna in a rip-rapped channel. River Research and Applications 18:321-330.

Loreau, M., N. Mouquet, and A. Gonzalez. 2003. Biodiversity as spatial insurance in heterogeneous landscapes. Proceedings of the National Academy of Sciences USA 100:12765-12770.

Louhi, P., H. Mykrä, R. Paavola, A. Huusko, T. Vehanen, A. MäkiPetäys, and T. Muotka. 2011. Twenty years of stream restoration in Finland: little response by benthic macroinvertebrate communities. Ecological Applications 21:1950-1961.

Louhi, P., J. S. Richardson, and T. Muotka. 2017. Sediment addition reduces the importance of predation on ecosystem functions in experimental stream channels. Canadian Journal of Fisheries and Aquatic Sciences 74:32-40.
MacArthur, R. H. 1965. Patterns of species diversity. Biological Reviews 40:510-533.

Magbanua, F. S., C. R. Townsend, K. J. Hageman, and C. D. Matthaei. 2013. Individual and combined effects of fine sediment and the herbicide glyphosate on benthic macroinvertebrates and stream ecosystem function. Freshwater Biology 58:1729-1744.

Marttila, M., P. Louhi, A. Huusko, A. Mäki-Petäys, T. Yrjänä, and T. Muotka. 2016. Long-term performance of in-stream restoration measures in boreal streams. Ecohydrology 9:280289.

Matthaei, C. D., F. Weller, D. W. Kelly, and C. R. Townsend. 2006. Impacts of fine sediment addition to tussock, pasture, dairy and deer farming streams in New Zealand. Freshwater Biology 51:2154-2172.

Matthaei, C. D., J. J. Piggot, and C. R. Townsend. 2010. Multiple stressors in agricultural streams: interactions among sediment addition, nutrient enrichment and water abstraction. Journal of Applied Ecology 47:639-649.

Matthiessen, B., E. Mielke, and U. Sommer. 2010. Dispersal decreases diversity in heterogeneous metacommunities by enhancing regional competition. Ecology 91:2022-2033.

Mouquet, N., and M. Loreau. 2003. Community patterns in sourcesink metacommunities. American Naturalist 162:544-557.

Muotka, T., and P. Laasonen. 2002. Ecosystem recovery in restored headwater streams: the role of enhanced leaf retention. Journal of Applied Ecology 39:145-156.

Muotka, T., and J. Syrjänen. 2007. Changes in habitat structure, benthic invertebrate diversity, trout populations and ecosystem processes in restored forest streams: a boreal perspective. Freshwater Biology 52:724-737.

Mustonen, K.-R., H. Mykrä, P. Louhi, A. Markkola, M. Tolkkinen, A. Huusko, N. Alioravainen, S. Lehtinen, and T. Muotka. 2016. Sediments and flow have mainly independent effects on multitrophic stream communities and ecosystem functions. Ecological Applications 26:2116-2129.

National Board of Waters. 1981. The analytical methods used by National Board of Waters. Report 213. National Board of Waters, Helsinki, Finland.

Oksanen, J., F. G. Blanchet, R. Kindt, P. Legendre, P. R. Minchin, R. B. O'Hara, G. L. Simpson, P. Solymos, M. H. H. Stevens, and H. Wagner. 2015. vegan: Community ecology package. R package version 2.3-2. https://cran.r-project.org, https://github.com/vega ndevs/vegan.

Palmer, M. A., K. L. Hondula, and B. J. Koch. 2014. Ecological restoration of streams and rivers: shifting strategies and shifting goals. Annual Review of Ecology, Evolution, and Systematics 45:247-269.

Peeters, E. T. H. M., B. T. M. J. Brugmans, J. A. J. Beijer, and R. J. M. Franken. 2006. Effect of silt, water and periphyton quality on survival and growth of the mayfly Heptagenia sulphurea. Aquatic Ecology 40:373-380.

Piggott, J. J., C. R. Townsend, and C. D. Matthaei. 2015. Climate warming and agricultural stressors interact to determine stream macroinvertebrate community dynamics. Global Change Biology 21:1887-1906.

Pinheiro, J., D. Bates, S. DebRoy, D. Sarkar, and the R Development Core Team. 2017. nlme: linear and nonlinear mixed effects models. R package version 3.1-131. http://www.r-project.org/pac kage $=$ nmle

Questad, E. J., and B. L. Foster. 2008. Coexistence through spatiotemporal heterogeneity and species sorting in grassland plant communities. Ecology Letters 11:717-726.

Rantala, M. J., J. Ilmonen, J. Koskimäki, J. Suhonen, and K. Tynkkynen. 2004. The macrophyte, Stratiotes aloides, protects larvae of dragonfly Aeshna viridis against fish predation. Aquatic Ecology 38:77-82.

Reed, D. C., P. T. Raimondi, M. H. Carr, and L. Goldwasser. 2000. The role of dispersal and disturbance in determining spatial heterogeneity in sedentary organisms. Ecology 81:2011-2026. 
Ricklefs, R. E. 1987. Community diversity: relative roles of local and regional processes. Science 235:167-171.

Roberts, D. W. 2012. labdsv: ordination and multivariate analysis for ecology. R package version 1.5-0. http://CRAN.R-project.org/ package $=$ labdsv

Sarremejane, R., H. Mykrä, N. Bonada, J. Aroviita, and T. Muotka 2017. Habitat connectivity and dispersal ability drive the assembly mechanisms of macroinvertebrate communities in river networks. Freshwater Biology 62:1073-1082.

Shaw, E. L., and J. S. Richardson. 2001. Direct and indirect effects of pulse duration on stream invertebrate assemblages and rainbow trout (Oncorhynchus mykiss) growth and survival. Canadian Journal of Fisheries and Aquatic Sciences 58:2213-2221.

Stein, A., K. Gerstner, and H. Kreft. 2014. Environmental heterogeneity as a universal driver of species richness across taxa, biomes and spatial scales. Ecology Letters 17:866-880.

Sundermann, A., M. Gerhardt, H. Kappes, and P. Haase. 2013. Stressor prioritisation in riverine ecosystems: Which environmental factors shape benthic invertebrate assemblage metrics? Ecological Indicators 27:83-96.

Suren, A. M. 1993. Bryophytes and associated invertebrates in firstorder alpine streams of Arthur's Pass, New Zealand. New Zealand Journal of Marine and Freshwater Research 27:479-494.

Suren, A. M., and M. J. Winterbourn. 1991. Consumption of aquatic bryophytes by alpine stream invertebrates in New Zealand. New Zealand Journal of Marine and Freshwater Research 25:331-343.

Suurkuukka, H., R. Virtanen, V. Suorsa, J. Soininen, L. Paasivirta, and T. Muotka. 2014. Woodland key habitats and stream biodiversity: does small-scale terrestrial conservation enhance the protection of stream biota? Biological Conservation 170:10-19.

Syvitski, J. P. M., C. J. Vörösmarty, A. J. Kettner, and P. Green. 2005. Impact of humans on the flux of terrestrial sediment to the global coastal ocean. Science 308:376-380.

Taniguchi, H., S. Nakano, and M. Tokeshi. 2003. Influences of habitat complexity on the diversity and abundance of epiphytic invertebrates on plants. Freshwater Biology 48:718-728.

Tews, J., U. Brose, V. Grimm, K. Tielbörger, M. C. Wichmann, M. Schwager, and F. Jeltsch. 2004. Animal species diversity driven by habitat heterogeneity/diversity: the importance of keystone structures. Journal of Biogeography 31:79-92.

Tonkin, J. D., S. Stoll, A. Sundermann, and P. Haase. 2014. Dispersal distance and the pool of taxa, but not barriers, determine the colonization of restored river reaches by benthic invertebrates. Freshwater Biology 59:1843-1855.

Tornwall, B. M., C. M. Swan, and B. L. Brown. 2017. Manipulation of local environment produces different diversity outcomes dep- ending on location within a river network. Oecologia 184: 663-674.

Townsend, C. R., S. S. Uhlmann, and C. D. Matthaei. 2008. Individual and combined responses of stream ecosystems to multiple stressors. Journal of Applied Ecology 45:1810-1819.

Turunen, J., T. Muotka, K.-M. Vuori, S. M. Karjalainen, J. Rääpysjärvi, T. Sutela, and J. Aroviita. 2016. Disentangling the responses of boreal stream assemblages to low stressor levels of diffuse pollution and altered channel morphology. Science of the Total Environment 544:954-962.

Turunen, J., J. Aroviita, H. Marttila, P. Louhi, T. Laamanen, M. Tolkkinen, P.-L. Luhta, B. Kløve, and T. Muotka. 2017. Differential responses by stream and riparian biodiversity to in-stream restoration of forestry-impacted streams. Journal of Applied Ecology 54:1505-1514.

Vannette, R. L., and T. Fukami. 2017. Dispersal enhances beta diversity in nectar microbes. Ecology Letters 20:901-910.

Venail, P. A., R. C. MacLean, T. Bouvier, M. A. Brockhurst, M. E. Hochberg, and N. Mouquet. 2008. Diversity and productivity peak at intermediate dispersal rate in evolving metacommunities. Nature 452:210-214.

Wagenhoff, A., C. R. Townsend, and C. D. Matthaei. 2012. Macroinvertebrate responses along broad stressor gradients of deposited fine sediment and dissolved nutrients: a stream mesocosm experiment. Journal of Applied Ecology 49:892902.

Waters, T. F. 1995. Sediment in streams: sources, biological effects and control. American Fisheries Society Monograph 7:1-251.

Winking, C., A. W. Lorenz, B. Sures, and D. Hering. 2014. Recolonisation patterns of benthic invertebrates: a field investigation of restored former sewage channels. Freshwater Biology 59:1932-1944

Wood, P. J., and P. D. Armitage. 1997. Biological effects of fine sediment in the lotic environment. Environmental Management 21:203-217.

Yang, Z., X. Liu, M. Zhou, D. Ai, G. Wang, Y. Wang, C. Chu, and J. T. Lundholm. 2015. The effect of environmental heterogeneity on species richness depends on community position along the environmental gradient. Scientific Reports 5:1-7.

Zuur, A. F., E. N. Ieno, N. J. Walker, A. A. Saveliev, and G. M. Smith. 2009. Mixed effects models and extensions in ecology with R. Statistics for biology and health. Springer-Verlag, New York, New York, USA.

Zweig, L. D., and C. F. Rabeni. 2001. Biomonitoring for deposited sediment using benthic invertebrates: a test on 4 Missouri streams. Journal of North American Benthological Society 20: 643-657.

SUPPORTING INFORMATION

Additional supporting information may be found online at: http://onlinelibrary.wiley.com/doi/10.1002/eap.1762/full

Data Availability

Data available from the Dryad Digital Repository: https://doi.org/10.5061/dryad.rr8t2j5. 